\title{
Mineração
}

\section{O rejeito da mineração de basalto no nordeste do Estado do Rio Grande do Sul: diagnóstico do problema}

\author{
(The residuals of basalt mining in the northeast of Rio \\ Grande do Sul, Brazil: evaluation of the problem)
}

\author{
Luciano Toscan \\ Prof. Msc. Administração, Universidade de Caxias do Sul (UCS) e Projeconsult Engenharia Ltda \\ E-mail: projeconsultnp@adylnet.com.br \\ Rubens Müller Kautzmann \\ Prof.Dr. Eng. Minas, Centro Universitário La Salle (Unilasalle) e $1^{\circ}$ Distrito/ DNPM \\ E-mail: rubesnmk@terra.com.br \\ Sydney Sabedot \\ Prof.Dr. Geólogo, Centro Universitário La Salle (Unilasalle).E-mail: sabedot@unilasalle.edu.br
}

\section{Resumo}

O objetivo do estudo foi conhecer o setor de extração de basalto, no município de Nova Prata, nordeste do Rio Grande do Sul, visando à qualificação dos procedimentos de gestão do setor. $\mathrm{O}$ universo estudado foi de 69 frentes de lavra (63\% das existentes no município), Trabalhou-se com dados secundários, principalmente dados econômicos do setor, e dados primários, coletados em visitas às pedreiras. Confirmaram-se a expressiva parcela de microempresas familiares, e o grande impacto da atividade sobre o meio ambiente. As empresas mineradoras se classificam em três grupos: 69 \% de pequeno porte; $20,5 \%$ de médio porte e $10 \%$ de grande porte. A produção é basicamente artesanal, empregando marretas, alavancas e talhadeiras. A produção de basalto no ano de 2004 foi de $60.000 \mathrm{~m}^{3}$ de produto acabado, como paralelepípedos, lajes, pedras para alicerces, entre outros. O levantamento dos rejeitos gerados nas atividades de mineração e acabamento estimou o volume anual de $52.400 \mathrm{~m}^{3}$, dos quais uma parte é coletada e transformada em brita e a outra permanece no local da pedreira, constituindo-se em passivo ambiental.

Palavras-chave: Lavra de basalto, rejeito, gestão de resíduos.

\begin{abstract}
The purpose of this study was to become familiarized with the basalt extraction sector, in Nova Prata, in the northeastern part of the State of Rio Grande do Sul, Brazil, and evaluate the sector's administrative proceedures. The researched area involved 69 of the 110 existing quarries in the area. Collected were secondary data, mainly economical, and primary data, which was obtained in situ regarding the quarries' small familly-owned companies and their environmental impacts.. The mining companies are classified in three groups: $69 \%$ are of small tonnage; $20,5 \%$ are of medium tonnage and $10 \%$ are of large tonnage. Production is obtained basically by hand, using mallets, crowbars and chisels. The production of Basalt in 2004 was about $60.000 \mathrm{~m}^{3}$ of refined product such as: pavement stones, flagstones, foundation blocks and so on. A survey of the residues produced in the mining and refining of the basalt showed that there is an estimated annual volume of $52.400 \mathrm{~m}^{3}$, of which only a small volume is recycled and transformed into crushed rock. The remaineder remains on the site, constituting an environmental liablility..
\end{abstract}

Keywords: Basalt quarry, solid residuals, waste management. 


\section{Introdução}

Foi na década de 1950 que imigrantes italianos, onde hoje se localiza a cidade de Nova Prata no noroeste do Rio Grande do Sul, iniciaram o aproveitamento econômico do basalto da Formação Serra Geral. Nova Prata é intitulada “Capital Nacional do Basalto”. Nos extratos de derrame vulcânico, com diaclasamento horizontal, é muito fácil a extração de placas de rocha, utilizando-se apenas ferramentas simples com alavancas. Os pedaços tabulares de 10 a $20 \mathrm{~cm}$ de espessura podem ser utilizados como elementos estruturais em construções e para calçamentos. A Figura 1 mostra a localização do distrito mineiro de Nova Prata (Santos, Maciel e Zir, 1998).

O basalto na forma de placas irregulares para calçamento, devido ao seu baixo custo e grande resistência, foi o produto que alavancou esse setor. Atualmente os produtos estão diversificados, com melhor acabamento, tanto para calçamento, quanto para piso e revestimento. Essa atividade de mineração, ainda em muitos casos, é intensificada em épocas de entressafra agrícola, constituindo-se, para muitos mineradores, um importante complemento da renda familiar da zona rural (Farina, 1986).

A abertura da pedreira de basalto é feita a partir da face exposta de um vale, compreendendo as etapas de: 1) descobertura da porção de solo, da rocha alterada e daquela sem diaclase horizontal e 2) o deslocamento do banco, ou seja, a liberação das placas de rocha (diaclasadas) com uso de explosivo de baixa intensidade (Toscan, Kautzmann, 2005). Uma vez individualizadas as placas de rocha, inicia-se o trabalho manual de separação das lajes, seleção e corte dos diversos tipos de produto. Os instrumentos utilizados são: cunhas, marretas, talhadeiras e formão. As lajes e peças são movimentadas ou carregadas na frente de lavra manualmente ou utilizando carros de mão (Toscan, Kautzmann, 2006). A Figura 2 mostra esquematicamente um perfil de pedreira de basalto, a meia encosta, que aproveita a exposição da zona do basalto tabular para estabelecer a frente de lavra (Toscan, Kautzmann, 2005).
A Figura 3 retrata uma pedreira de basalto, em meia encosta, em área de floresta natural, onde o dano ambiental da atividade e a deposição de rejeitos são evidentes.

Esse trabalho apresenta a compilação dos resultados obtidos no diagnóstico inicial desse setor mineiro, caracterizando a empresa minerados e os rejeitos da mineração. A pesquisa visa a contribuir na condução de ações de gestão dos rejeitos que possibilitem o desenvolvimento sustentável da atividade.

\section{Metodologia}

A caracterização empresarial do setor foi realizada a partir de dados secundários e primários. A pesquisa utilizou alguns critérios próprios para facilitar a classificação das empresas mineradoras de basalto, como o porte, relacionado ao número de funcionários ou trabalhadores, sem qualquer relação ao faturamento ou produção declarada pelas empresas.

O levantamento dos dados primários em campo foi estruturado na forma de questionário, que o pesquisador preencheu, e medidas expeditas. A área pesquisada

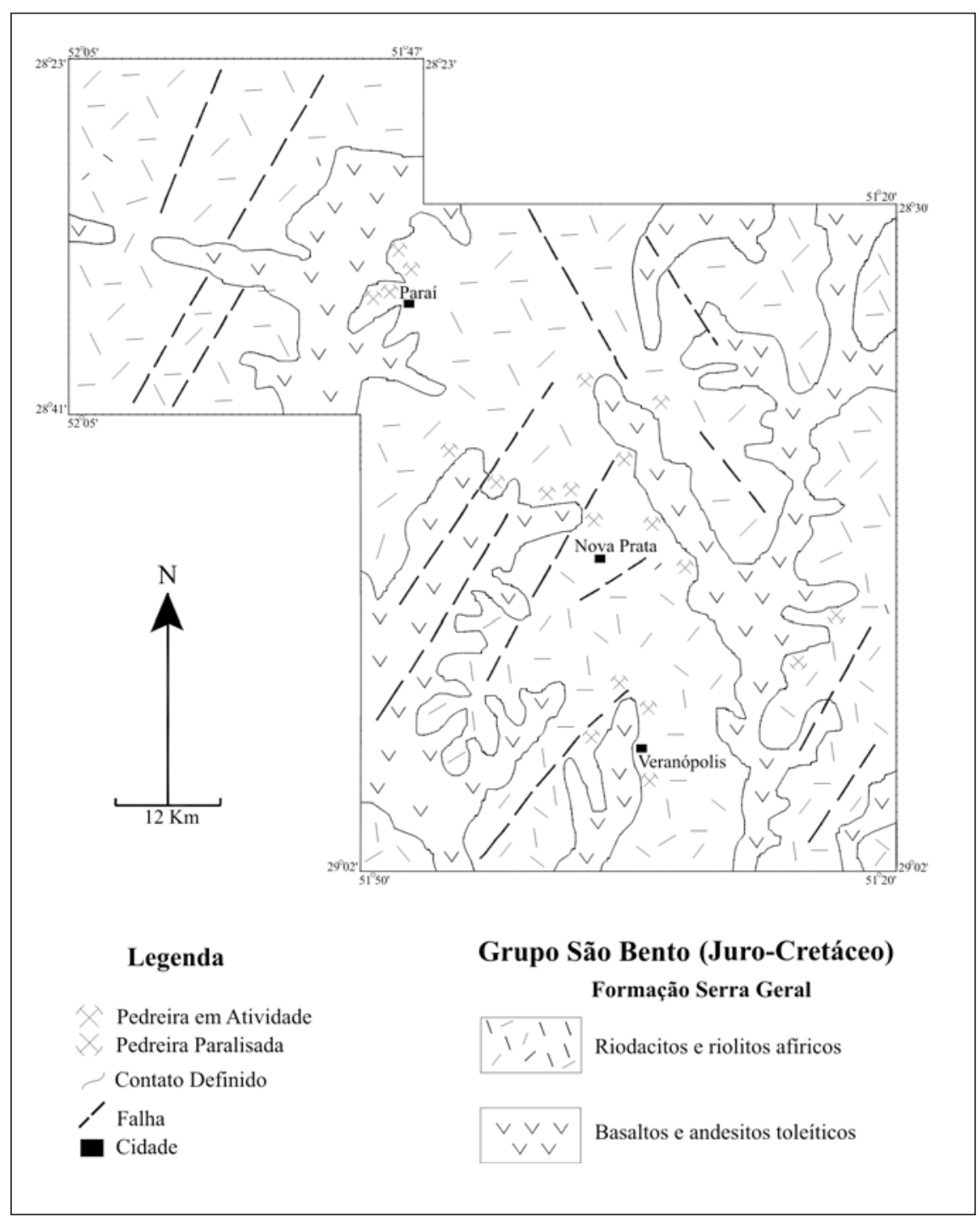

Figura 1 - Mapa Geológico do Distrito Mineiro de Nova Prata. 
contemplou 69 frentes de lavra (pedreiras), das 110 existentes no município, que pertencem a 39 empresas, das 83 estabelecidas em Nova Prata. Esse universo foi considerado satisfatório para fins do estudo realizado (63\% das frentes de lavra e $47 \%$ das empresas).

O questionário de campo colheu dados sócio-econômicos e de produção e geração de rejeitos. A estimativa dos quantitativos da geração e disposição de rejeitos foi realizada a partir de: medições utilizando trena e contagem de passos (convertidos para metros) e trena, para medir, compor formas simples dos depósitos de rejeitos para calcular seus volumes; e informação utilizando unidades de medida próprias dos mineradores:

- 1 biga (veículo motorizado c/caçamba) $=3 \mathrm{~m}^{3}$ de retalho ou rejeito. Exemplo: Três caminhões por semana $=9 \mathrm{~m}^{3}$ ou $36 \mathrm{~m}^{3}$ ao mês de retalho ou rejeito.

- 1 Caminhão caçamba (com 2 eixos) $=6 \mathrm{~m}^{3}$ de retalho ou rejeito.

- 1 concha de retroescavadeira (draga) $=1 \mathrm{~m}^{3}$ de retalho ou rejeito.

- 1 concha da carregadeira $=3 \mathrm{~m}^{3}$ de retalho ou rejeito

\section{Resultados e discussão}

O município de Nova Prata possui um perfil econômico diversificado, compreendendo indústria, comércio, mineração e agricultura. A indústria da borra, representada pela empresa Vipal, representa $70 \%$ da arrecadação do município, enquanto a mineração e beneficiamento do basalto repondem por $10 \%$, conforme dados de 2004 publicados na Hierarquia Sócio-Econômica de Nova Prata e Nova Bassano. A seguir serão comentadas algumas caracteristicas do setor que permite conhecer sua dimensão e importância sócio-econômica.

Considerou-se como empresa pequena aquelas com até 05 funcionários na pedreira(s), empresa média, 05 a 10 funcionários na pedreira(s), e empresa grande aquelas com mais de 10 funcio-

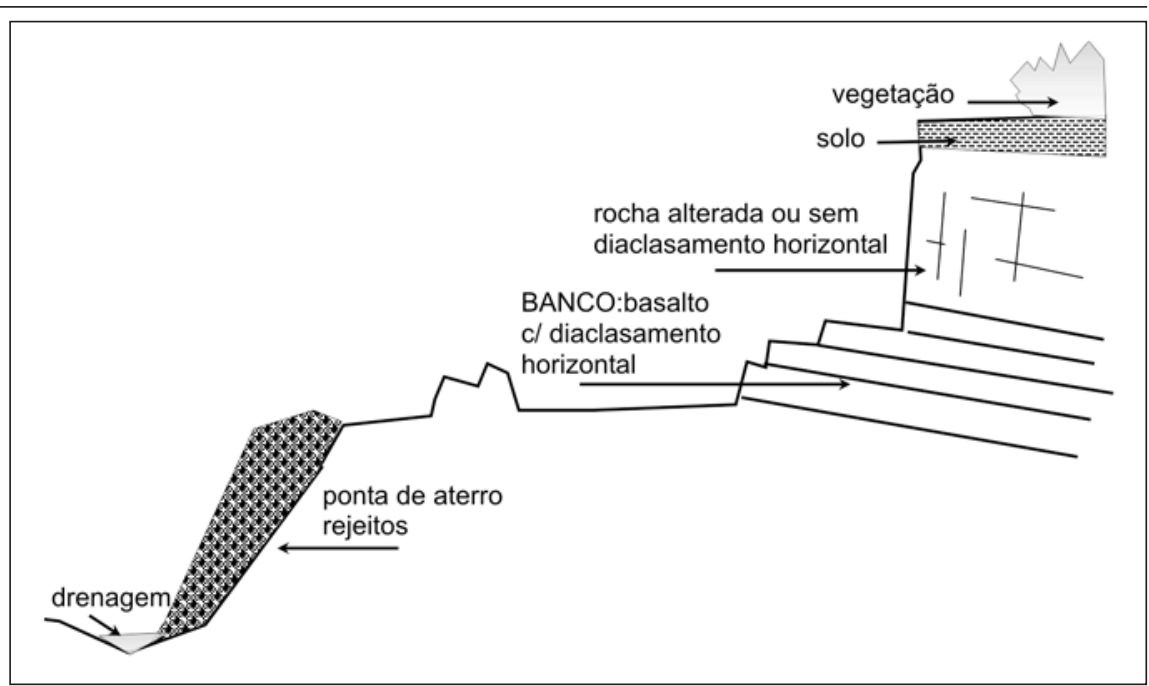

Figura 2 - Perfil mostrando uma frente de lavra típica de extração de basalto para laje.

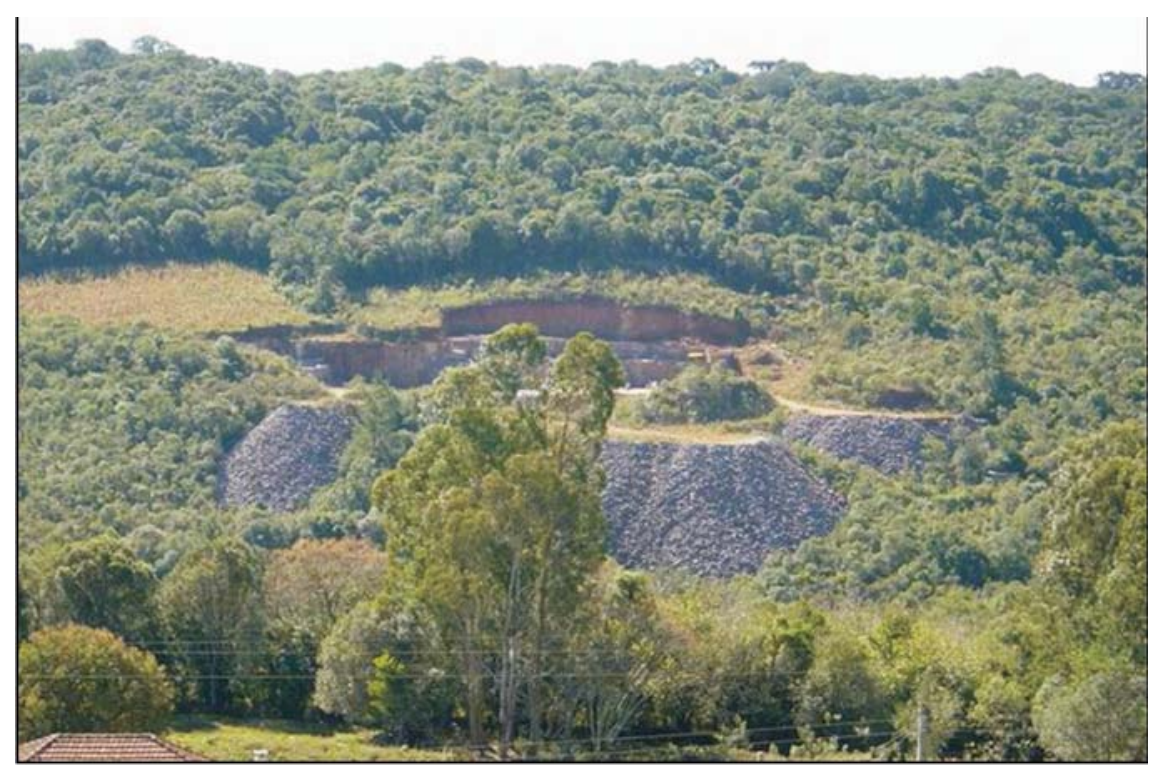

Figura 3 - Imagem de uma pedreira de basalto e seu contexto ambiental.

nários na pedreira(s). A Tabela 1 mostra a distribuição de tamanho entre as empresas pesquisadas.

Observa-se que as empresas de pequeno representam 70\% das empresas de extração pesquisadas, mostrando a característica de microempreendimento do setor. Nas empresas pequenas e médias, em regra, esses trabalhadores são contratados sem carteira assinada, sendo remunerados por porcentagem de produção. O número de trabalhadores está também associado ao potencial produtivo da pedreira e à capacidade financeira da empresa extratora.
A formação da cadeia produtiva de extração de basalto tem tido papel fundamental no processo de desenvolvimento do município de Nova Prata. Estima-se um total de 280 trabalhadores diretos no universo pesquisado e um total de 3 (três) mil empregos, entre diretos e indiretos na região (Revista do Basalto, 2000), o que, aliado à arrecadação, denota a importância dessa atividade e a necessidade de fomento ao seu desenvolvimento sustentável.

Para classificar as empresas por tipo de organização, Tabela 2, estabeleceramse duas categorias: empresa familiar, de- 
finida como àquela que opera apenas com os membros da uma família e parentes próximos, e empresa de subsistência, aquela que possui funcionários ou alugam "bancos" ou setores de uma pedreira a terceiros.

Nas empresas familiares, em regra, os membros da família desenvolvem uma segunda atividade produtiva, ou remunerada, na atividade rural ou outro setor. Já as empresas de subsistência operam com poucos funcionários, na sua maioria sem qualificação.

A Tabela 3 apresenta a renda familiar de 85 entrevistados e aponta para o fato de que, em 2003, a maior concentração de renda ficou entre 2 e 4 salários mínimos.

A regularização das empresas pesquisadas é apresentada na Tabela 4. Em regra, o título minerário das empresas é o regime de Registro de Licenciamento (Departemanto Nacional de Produção Mineral - DNPM), obtido a partir da Autorização do Proprietário do Solo e Licenciamento Municipal. Esses dois níveis de autorização só serão consagrados com o Licenciamento Ambiental, de competência da Fundação Estadual de Proteção Ambiental - FEPAM.

A menor percentagem de $71 \%$ de empresas que possuem Licença Ambiental se deve às dificuldades de essa atividade se adequar às exigências ambientais em decorrência dos reais impactos e conflitos entre a mineração e a sustentabilidade ambiental. Em contrapartida, o percentual elevado de um tipo de autorização pública mostra o interesse do setor em se regularizar e a importância do Sindicato do Setor para que a atividade seja empreendida de forma regularizada.

Quanto à produção de basalto, de acordo com o Sindicato do Setor, em 2004, a produção anual foi estimada em 60.000 $\mathrm{m}^{3}$ de produtos de basalto. A Tabela 5 apresenta os quatro produtos principais produzidos na região.

A característica do jazimento e propriedades petrológicas possibilitam a fácil obtenção e confecção de vários ti-
Tabela 1 - Tamanho das empresas pesquisadas.

\begin{tabular}{l|l|l}
\hline \multicolumn{1}{c|}{ Empresas } & $\mathbf{N}^{\circ}$ & $\%$ \\
\hline Total de empresas pequenas & 27 & $69,20 \%$ \\
\hline Total de empresas médias & 8 & $20,50 \%$ \\
\hline Total de empresas grandes & 4 & $10,30 \%$ \\
\hline Total de empresas & 39 & $100.0 \%$ \\
\hline
\end{tabular}

Tabela 2 - Característica familiar das empresas de extração de basalto.

\begin{tabular}{l|l|c}
\hline \multicolumn{1}{c|}{ Empresas } & $\mathbf{N}^{\circ}$ & $\%$ \\
\hline Total de empresas pesquisadas & 39 & $100 \%$ \\
\hline Empresas familiares & 11 & $28,2 \%$ \\
\hline Empresas de Subsistência & 27 & $69,2 \%$ \\
\hline Empresas não cadastradas & 1 & $2,6 \%$ \\
\hline
\end{tabular}

Tabela 3 - Renda familiar.

\begin{tabular}{c|c|c}
\hline Renda Familiar & Quantidade & $\%$ \\
\hline 1 a 2 & 6 & 7 \\
\hline 2 a 4 & 57 & 67 \\
\hline 4 a 6 & 17 & 5 \\
\hline 6 a 8 & 4 & 1 \\
\hline 08 ou mais & 1 & 100 \\
\hline Total & 85 &
\end{tabular}

(Fonte: Rui, B. 2003).

Tabela 4 - Licença Municipal, Registro Mineral (DNPM) e Licença Ambiental (FEPAM) das pedreiras pesquisadas.

\begin{tabular}{l|c|c}
\hline \multicolumn{1}{c|}{ Empresas } & $\mathbf{N}^{\circ}$ & $\%$ \\
\hline Empresas pesquisadas & 31 & 100 \\
\hline Empresas com Licença Municipal & 29 & 94 \\
\hline Empresas sem Licença Municipal & 2 & 6 \\
\hline Empresas com Registro no DNPM & 27 & 87 \\
\hline Empresas sem Registro no DNPM & 4 & 13 \\
\hline Empresas com Licença da FEPAM & 22 & 71 \\
\hline Empresas sem Licença da FEPAM & 9 & 29 \\
\hline
\end{tabular}


pos de produto de revestimento (em forma e tamanho). Até meados da década de 1990, o carro-chefe da produção se constituiu nos retalhos para calçamento (elementos de forma irregular), obtidos simplesmente pela quebra do extrato diaclasado. Esse produto é ainda o de menor valor, baixa remuneração do produtor, porém produzido manualmente e que remunera pouco o microprodutor descapitalizado. Perdeu a posição para as peças regulares (lajes), que apresentam vantagens na aplicação e durabilidade da obra, sendo produzidas pelo menor número de empresas, estas mais capitalizadas.

Outro aspecto importante é que o avanço das pedreiras, em zonas onde o diaclasamento horizontal é imperfeito, o que implica a necessidade de readequação dos produtos e leva a maiores dificuldades de obtenção das placas horizontais. Esse novo cenário promove a alteração do perfil de produção, em que o paralelepípedo vem conquistando o mercado de revestimento (pisos), associando durabilidade ao baixo valor do produto na jazida. Algumas empresas já conseguem maximizar a utilização de aparas da produção de laje para confeccionar paralelepípedos de vários tamanhos, maximizando a utilização do basalto.

Os rejeitos das pedreiras podem ser classificados conforme a etapa de produção: lavra ou beneficiamento, correspondendo a distintas tipologias de material:

1) Rejeitos da atividade de lavra: Estimouse uma produção anual de $52.400 \mathrm{~m}^{3}$ :

- Solo de cobertura: substrato original de fixação da mata ou dos cultivos, podendo atingir espessuras de 0 a $1 \mathrm{~m}$, constituído de material inconsolidado da alteração do basalto e matéria orgânica (com boa fertilidade) no horizonte A. Esse horizonte de solo é retirado com escavadeiras ou tratores de lâmina na etapa de abertura e avanço da frente de lavra.

- Rocha alterada do horizonte R do solo. Para a retirada desse material é empregado o desmonte por explosivos e limpeza, utilizando escavadeiras ou tratores.

- Rocha sã que não apresenta o diaclasamento horizontal. Desmontado utilizando explosivos, esse material rochoso pode ter características geológicas idênticas ao horizonte R. Quando ocorre a interrupção do diaclasamento, esta feição geológica é chamada de cordão e pode inviabilizar a continuidade da lavra.

2) Rejeitos da atividade de beneficiamento ou acabamento:

Os trabalhos de acabamento geram mensalmente $7.000 \mathrm{~m}^{3}$ de rejeitos limpos, correspondendo a $12 \%$ da produção total de elementos de basalto (Tabela 4). Os rejeitos gerados no processo de acabamento, considerados como etapas do beneficiamento, constituem-se, principalmente, de lascas de rocha. A tipologia granulométrica desse rejeito é apresen- tada na Tabela 6, correlacionada ao tipo de produto que a gerou.

O rejeito limpo pode ser utilizado na produção de brita ou na confecção de elementos regulares menores, como ladrilhos e mesmo na produção de peças esculpidas de artesanato. Por sua vez, nas usinas de britagem, o pó de brita não tem demanda compatível com sua produção, tornando-se, também, um resíduo. O pó de brita apresenta a granulometria de areias e pode substituir, parcialmente, a areia quartzosa na confecção de concretos, ou mistura asfáltica.

A Tabela 7 apresenta a estimativa das quantidades de rejeitos gerados pelas pedreiras de laje de basalto e os quantitativos existentes atualmente em depósitos e descartados em locais impróprios (passivos). Não foi possível avaliar a produção mensal de rejeito originados do avanço das lavras ou de novas frentes de lavra.

Tabela 5 - Produção de elementos de basalto em 2004 - Nova Prata - RS.

\begin{tabular}{l|c|c}
\hline \multicolumn{1}{c|}{ Principais Produtos } & Volume Produzido $\left(\mathbf{m}^{\mathbf{3}}\right)$ & $\mathbf{( \% )}$ \\
\hline Paralelepípedos & 30.000 & 50 \\
\hline Lajes & 6.000 & 10 \\
\hline Retalhos para calçamento & 12.000 & 20 \\
\hline Pedras para alicerce & 6.000 & 10 \\
\hline Outros & 6.000 & 10 \\
\hline Total Produzido & 60.000 & 100 \\
\hline
\end{tabular}

Tabela 6 - Característica dos rejeitos gerados na produção de produtos acabados de basalto.

\begin{tabular}{l|c}
\hline \multicolumn{1}{c|}{ Produtos } & Dimensões da lasca do rejeito (cm) \\
\hline Paralelepípedos & Lascas de 3 a 10 \\
\hline Pedras para alicerce & Lascas de 3 a12 \\
\hline Lajes & Retalhos 5 a 20 \\
\hline Pedras Irregulares (Retalhos) & Lascas de 3 a 12 \\
\hline Brita & Pó de brita $<2,5 \mathrm{~mm}$ \\
\hline
\end{tabular}

REM: R. Esc. Minas, Ouro Preto, 60(4): 657-662, out. dez. 2007 
Os rejeitos de acabamento, da ordem de 7.000 m³/mês, vêm sendo reaproveitados na produção de brita. No período do estudo, foram coletados $3.900 \mathrm{~m}^{3 /}$ mês de rejeitos, acumulados nas frentes de lavra, e $2.400 \mathrm{~m}^{3} /$ mês, retirados de depósitos, totalizando $6.300 \mathrm{~m}^{3} / \mathrm{mês}$. Portanto, nesse período, 55,7\% dos rejeitos gerados foram destinados a aterros, incrementando os depósitos de rejeito limpo em $1 \%$ ao mês. Já o volume de rejeitos retirado desse tipo de depósito para fins de britagem representou $0,8 \%$, ou seja, o incremento dos depósitos ainda é positivo, em 0,02\% ou 700 m³/mês.

É necessário salientar que a coleta de rejeitos está condicionada às pedreiras e depósitos próximos às instalações de britagem, havendo locais onde ocorre a redução e outros locais, o incremento dos depósitos de rejeitos. Registrase, também, que os rejeitos mistos em passivos não são utilizados para produção de brita, perdurando, assim, a condição agressiva ao meio ambiente natural.

O trabalho não chegou a estudar o componente de mercado importante e fundamental para delinear ações de gestão para o setor. A geração de novos produtos ou otimização da produção, principalmente na utilização dos rejeitos, deve vir acompanhada da abertura de novos mercados. Um exemplo desse potencial é a comercialização de ladrilhos para países da Europa.

\section{Considerações finais}

Os dados e informações obtidos na pesquisa de campo e nas entrevistas são estimativas que necessitam aprimoramento dos métodos de correlação e maior tempo de amostragem. Contudo permitem uma fotografia do setor e seus rejeitos.
Tabela 7 - Estimativa de volumes de rejeitos gerados e existentes em depósitos e passivos no município de Nova Prata.

\begin{tabular}{l|c|c}
\hline \multicolumn{1}{c|}{ Rejeitos } & mil $\mathbf{~ m}^{\mathbf{3}}$ & $\%$ \\
\hline Rejeitos de acabamento (mensal) & 7 & \\
\hline Rejeito limpo (lascas de rocha sã) em depósito & 285 & $44 \%$ \\
\hline Rejeito misto (rocha sã, alterada e solo) em passivos & 362 & $56 \%$ \\
\hline Total de Rejeitos (misto + limpo) & 647 & $100 \%$ \\
\hline
\end{tabular}

A continuidade dessa pesquisa deverá ir aperfeiçoando o método de quantificação da geração de rejeitos e medições de depósitos e passivos existentes, visando melhor avaliar as potencialidades de mercado para produtos derivados, como: brita e areia de brita, ou paralelepípedos e ladrilhos, agregando valor aos produtos e maximizando o uso do bem mineral. Análise de custos e usos dos rejeitos na recuperação de passivos também merecem estudo. Assim, será possível estabelecer ações de gestão factíveis à minimização dos impactos e adequação da mineração do basalto ao seu desenvolvimento sustentável.

\section{Agradecimentos}

Os autores agradecem ao Sindicato da Indústria da Extração de Pedreiras de Nova Prata pelo apoio que vem dando à realização desse trabalho.

\section{Referências bibliográficas}

FARINA, G. História de Nova Prata. Caxias do Sul: EDUCS, 1986. 301p.

HIERARQUIA SÓCIO-ECCONÔMICA DE NOVA PRATA E NOVA BASSANO: Ano base 2003. Ed 21. 2004.

SANTOS, E.L., MACIEL, L.A.C., ZIR F., J.A. Distritos Mineiros do Estado do Rio Grande do Sul, Distrito Mineiro Nova Prata. Brasília: DNPM, 1998. p. 13-14.

REVISTA DO BASALTO. Sindicato da Indústria da Extração de Pedreiras de Nova Prata e Região, 2000.

RUI, Betânia Rita. Evolução econômica no período de 1995 a 2002 para o setor de extração de basalto de Nova Prata. Caxias do Sul: UCS, 2003. (Monografia para Conclusão de Curso de Ciências Econômicas).

TOSCAN, L., KAUTZMANN, R.M. Diagnóstico da mineração de basalto e seu rejeito no município de Nova Prata - RS: 1- estudo setorial. INTERNATIONAL CONGRESS ON ENVIRONMENTAL PLANNING AND MANAGEMENT. Brasília, 2005.

TOSCAN, L., KAUTZMANN, R.M. Diagnóstico da mineração de basalto e seu rejeito, no município de Nova Prata RS; 2- estudo do rejeito. SIMPÓSIO INTERNACIONAL DE QUALIDADE AMBIENTAL, 5. Porto Alegre, 2006.

\section{REM - Revista Escola de Minas www.rem.com.br}

